\title{
A highly cognitive demanding working memory task may prevent the development of nociceptive hypersensitivity
}

Citation for published version (APA):

Torta, D. M., De Laurentis, M., Eichin, K. N., von Leupoldt, A., van den Broeke, E. N., \& Vlaeyen, J. W. S. (2020). A highly cognitive demanding working memory task may prevent the development of nociceptive hypersensitivity. Pain, 161(7), 1459-1469. https://doi.org/10.1097/j.pain.0000000000001841

Document status and date:

Published: 01/07/2020

DOI:

10.1097/j.pain.0000000000001841

Document Version:

Publisher's PDF, also known as Version of record

\section{Document license:}

Taverne

Please check the document version of this publication:

- A submitted manuscript is the version of the article upon submission and before peer-review. There can be important differences between the submitted version and the official published version of record.

People interested in the research are advised to contact the author for the final version of the publication, or visit the DOI to the publisher's website.

- The final author version and the galley proof are versions of the publication after peer review.

- The final published version features the final layout of the paper including the volume, issue and page numbers.

Link to publication

\footnotetext{
General rights rights.

- You may freely distribute the URL identifying the publication in the public portal. please follow below link for the End User Agreement:

www.umlib.nl/taverne-license

Take down policy

If you believe that this document breaches copyright please contact us at:

repository@maastrichtuniversity.nl

providing details and we will investigate your claim.
}

Copyright and moral rights for the publications made accessible in the public portal are retained by the authors and/or other copyright owners and it is a condition of accessing publications that users recognise and abide by the legal requirements associated with these

- Users may download and print one copy of any publication from the public portal for the purpose of private study or research.

- You may not further distribute the material or use it for any profit-making activity or commercial gain

If the publication is distributed under the terms of Article 25fa of the Dutch Copyright Act, indicated by the "Taverne" license above, 


\title{
A highly cognitive demanding working memory task may prevent the development of nociceptive hypersensitivity
}

\author{
Diana M. Torta ${ }^{a, b, \star}$, Martina De Laurentis ${ }^{c}$, Katharina Naomi Eichin ${ }^{a}$, Andreas von Leupoldt ${ }^{a}$, \\ Emanuel N. van den Broeke ${ }^{b}$, Johan W.S. Vlaeyen ${ }^{a, d}$
}

\begin{abstract}
Whether, how, and which cognitive factors modulate the development of secondary hypersensitivity/hyperalgesia after central sensitization is not fully understood. Here, we tested, in 3 subsequent experiments, whether being engaged in non-pain-related cognitive demanding tasks: (1) lessens the amount of hypersensitivity developed after an experimental procedure sensitizing nociceptive pathways; and (2) modulates cortical responses to somatosensory stimuli (measured by electroencephalography, EEG). In the first experiment, we validated a novel model in humans using low-frequency stimulation of the skin and demonstrated that it was able to successfully induce hypersensitivity to mechanical pinprick stimuli in the area surrounding the sensitized site. In the second and third experiments, we engaged participants in tasks of increasing difficulty (the Eriksen Flanker Task in experiment 2, and a modified N-back task in experiment 3). We observed that hypersensitivity to mechanical stimuli still developed in experiment 2, that is, the pinprick stimuli applied on the sensitized arm were perceived as more intense after low-frequency stimulation. By contrast, no statistically significant enhancement of mechanical hypersensitivity was observed in experiment 3, indicating that, at the group level, being engaged in a difficult N-back task may interfere with the development of mechanical hypersensitivity. Contrary to previous studies, which have used different methods to induce sensitization, we did not observe any increase in the cortical response to somatosensory stimuli applied on the sensitized arm. We conclude that (1) the development of pinprick hypersensitivity is modulated by the concomitant execution of a difficult N-back task, and (2) the enhancement of cortical responses to somatosensory stimuli is related to the method used to induce central sensitization.
\end{abstract}

Keywords: Central sensitization, Cognition, Mechanical hypersensitivity, EEG

\section{Introduction}

The optimal balance between shielding goals and attending to dangerous signals is crucial for survival. Nociceptive stimuli are salient, signal potential danger, and capture attention. ${ }^{5}$ This attentional capture is reduced when participants perform tasks requiring mental operations that are sufficiently engaging, difficult, and unrelated to pain. ${ }^{12,13,19,29}$ Previous research has shown that cognitive load reduces pain reports and brain responses to brief transient nociceptive stimuli, and that it slows down reaction times to these stimuli. ${ }^{13,16}$ Indeed, performing a task recruits cognitive resources that are no longer allocated to the concomitant incoming nociceptive stimulus, shielding the task

$\overline{\text { Sponsorships or competing interests that may be relevant to content are disclosed }}$ at the end of this article.

M. De Laurentis and K.N. Eichin contributed equally to this work.

${ }^{a}$ Health Psychology, KU Leuven, Leuven, Belgium, ${ }^{b}$ Institute of Neuroscience, UCLouvain, Brussels, Belgium, ${ }^{c}$ Department of Neuroscience, University of Turin, Turin, Italy, ${ }^{d}$ Experimental Health Psychology, Maastricht University, Netherlands

${ }^{*}$ Corresponding author. Address: Health Psychology, KU Leuven, Tiensestraat 102, 3000, Leuven, Belgium. Tel.: +32 163766 23. E-mail address:

diana.torta@kuleuven.be (D.M. Torta).

Supplemental digital content is available for this article. Direct URL citations appear in the printed text and are provided in the HTML and PDF versions of this article on the journal's Web site (www. painjournalonline.com).

PAIN 161 (2020) 1459-1469

(C) 2020 International Association for the Study of Pain

http://dx.doi.org/10.1097/j.pain.0000000000001841 performance from the disruptive effects of nociceptive input. ${ }^{13,19}$ This possibility allows us to keep on pursuing our goals even in the face of pain. ${ }^{29}$

Animal studies have shown that repeated and/or intense peripheral nociceptive input triggers an increase in the excitability of spinal nociceptive neurons, a phenomenon referred to as central sensitization (CS) (eg, the "increased responsiveness of nociceptive neurons in the central nervous system to their normal or subthreshold input ${ }^{11}$ ). In humans, a direct measure of such excitation is not possible, and secondary hyperalgesia/hypersensitivity to mechanical stimuli (eg, the increased sensitivity developing, after tissue injury, in the surrounding uninjured skin) is taken as one of its manifestations. In this paper we will use the term hypersensitivity when the increased perception refers to nociceptive stimuli which are not perceived as painful at baseline, and hyperalgesia as the increased perception to stimuli which are perceived as painful at the baseline. See Ref. 30 for a discussion on this point. Whether, how, and which cognitive factors modulate the development of secondary hypersensitivity after CS is not fully understood. A few studies have addressed this key question by experimentally inducing CS in healthy volunteers. Their results suggest that positive expectations, induced through placebo manipulations, reduce the dimension of the area of hyperalgesia, ${ }^{14}$ whereas negative expectations induced by verbal suggestion increase the amount of hypersensitivity/ hyperalgesia. ${ }^{31}$ Furthermore, it has been reported that brief sessions of pain-focused cognitive behavioral therapy, aimed at reducing negative cognitions, led to a smaller extent of the hyperalgesic site as compared to a non-pain-specific training. ${ }^{17}$ 
It is unknown which cognitive mechanisms can interfere with the development of CS, and the increase in cortical responses to somatosensory stimuli observed after sensitization. ${ }^{30,34,36-38}$ It can be hypothesized that shielding cognition from the sensitization procedure would lead to less attentional resources engaged in the perception of the intense/prolonged nociceptive stimuli, and possibly reduce both hypersensitivity and the increase in cortical responses. This would constitute evidence that attention directed to the sensitizing stimuli is a major contributor to the genesis of secondary hyperalgesia. To test this hypothesis, we performed 3 separate electroencephalographic (EEG) and behavioral experiments. In the first, we validated a novel protocol to induce hypersensitivity in humans by using low-frequency stimulation (LFS). ${ }^{7}$ The same protocol was then used in the following experiments in which engaging and pain-unrelated cognitive tasks of different difficulty were administered during LFS.

\section{Materials and methods}

\subsection{Participants}

Participants were recruited at the KU Leuven and were naive to the aims of research. Their participation was rewarded with either course credits or money (20 Euros for a 2.30-hour experiment). Informed written consent was obtained before the beginning of the study, which had been approved by the university ethical committee (G-2016 11669). Sample size was calculated on the basis of previous studies and available literature. ${ }^{31}$ By signing the exclusion criteria, participants confirmed that they did not suffer from cardiovascular or respiratory diseases, chronic pain, acute pain at the time of testing, hearing problems, and diagnosis of neurological and/or psychiatric syndromes. Participants were also excluded if they were pregnant, regular drug users, on stable medication (with the exception of contraceptive pill), significantly sleep deprived (slept less than 6 hours the night before the experiment), and if they had taken anti-inflammatory drugs $<12$ hours before the experiment.

Sixty-four healthy participants were enrolled; 4 stopped during the sensitization procedure due to unbearable pain ( 2 in experiment 1 and 2 in experiment 2). The final sample was composed of 60 participants: 20 took part in experiment 1 (14 women, 6 men; median age 22 years, range 19-37), 19 in experiment 2 (15 women, 4 men; median age 22 years, range 18-40), and 21 in experiment 3 (10 women, 11 men; median age 26, range 19-36). None of the participants took part in more than one experiment.

\subsection{Measures}

\subsubsection{Questionnaires}

Before the beginning of the experiment, participants filled in questionnaires assessing the level of intolerance of uncertainty, positive/negative affect and optimism, pain catastrophizing (eg, Intolerance of Uncertainty Scale, ${ }^{3}$ Positive and Negative Affect Schedule, ${ }^{41}$ Life Orientation Test-Revised, ${ }^{18}$ and Pain Catastrophizing Scale $\left.^{23}\right)$. Questionnaires are part of larger prospective ongoing study. Therefore, the results will be presented here only in a descriptive way. A description of the questionnaires is provided in the supplementary material (available at http://links.lww.com/PAIN/A968).

\subsubsection{Stimuli}

\subsubsection{Low-frequency stimulation}

Low-frequency stimulation was used to induce secondary mechanical hypersensitivity, a hallmark of $\mathrm{CS}^{28}$ It consisted of 2 minutes of electrical stimulation at $2 \mathrm{~Hz}$ (pulse width $2 \mathrm{~ms}$ ). ${ }^{7}$
The pulses were generated by a constant-current electrical stimulator (DS7; Digitimer Ltd, Welwyn Garden City, United Kingdom). The stimuli were applied by using a specifically designed electrode composed of 16 blunt stainless steel pins with a diameter of $0.2 \mathrm{~mm}$, protruding $1 \mathrm{~mm}$ from the base. , $^{98}$ The pins were placed in a circle with a diameter of $10 \mathrm{~mm}$ and served as cathode. The stainless steel reference electrode, the anode, was placed surrounding the cathode and had an inner diameter of $22 \mathrm{~mm}$ and an outer diameter of $40 \mathrm{~mm}$.

The intensity of stimulation was determined individually at 15 times the absolute detection threshold to a single pulse. The $15 \times$ threshold was established after running a pilot experiment assessing the compromise between feasibility and effectiveness of LFS using the $20 \times$ and $10 \times$ detection thresholds.

\subsubsection{Mechanical hypersensitivity}

Mechanical hypersensitivity was tested by using pinprick stimuli, which were applied using a calibrated stainless steel pinprick stimulator exerting a force of $128 \mathrm{mN}$ (MRC Systems, Heidelberg, Germany) and having a 0.25-mm probe diameter.

\subsubsection{Electrocutaneous innocuous stimuli}

Electrocutaneous innocuous stimuli consisted of 0.5-ms constant-current square waves electrical pulses (generated by a DS7 stimulator; Digitimer Ltd). The stimuli were delivered using a bar stimulating electrode (Digitimer Ltd), which consisted of 2 durable stainless steel disk electrodes of a 8-mm diameter with 30-mm spacing. The electrode was held by means of a Velcro strap. Both mechanical and electrocutaneous stimuli were applied on the volar forearm, $1.5 \mathrm{~cm}$ from the LFS stimulated region (and the homologue region of the control arm).

\subsubsection{EEG recording and analysis}

The EEG was recorded at a 1-kHz sampling rate using a 129channel amplifier and digitizer (Philips Electrical Geodesics, Inc, Eugene, OR). Analysis of the EEG data was performed using Letswave 6 (http://www.nocions.org/letswave). Extraencephalic channels likely to be contaminated by artifacts were excluded from subsequent analyses. ${ }^{11}$ These included the following leads (E44, E43, E38, E128, E127, E48, E49, E119, E126, E120, E114, E113, E121, and E125). Continuous EEG recordings were rereferenced to the average of the remaining leads; a $50-\mathrm{Hz}$ notch and a 0.5 to $30 \mathrm{~Hz}$ Butterworth zero phase filter were then applied. The data were segmented in 3-second epochs extending from -1 to +2 seconds relative to stimulus onset. Artifacts were removed from the signal using an independent component analysis. ${ }^{8}$ Baseline correction was performed subtracting the signal from the -1 to -0.1 seconds prestimulus interval; a further artifact correction eliminating epochs exceeding $100 \mu \mathrm{V}$ was performed. The obtained waveforms were then averaged to obtain for each participant and time point (TO, T1, and T2), 2 grand averages, one for the stimuli applied to the control arm and the other for the stimuli applied to the LFS arm. The latency and amplitude of the $\mathrm{N} 1$ and the P2 component of the somatosensory evoked potentials (SEPs) were identified at pooled electrodes around the vertex $\mathrm{Cz}$ (E129); pooled electrodes were E7, E31, E55, E80, E106, and E129 (Cz). The N1 was identified as the most negative peak between 0.07 and 0.2 seconds after stimulus, and the P2 as the most positive deflection after the N1 and occurring in an interval between 0.100 and 0.350 seconds. Waves were subsequently visually inspected to confirm the automatic procedure. 


\subsubsection{General experimental procedure}

The 3 experiments shared the same experimental procedure. For the nature of the study, ie, we first needed to validate the LFS procedure, the experiments were performed consecutively on 3 separate groups of participants. On arrival, participants signed the informed consent and the declaration regarding the exclusion criteria. Then, they completed the questionnaires.

The detection threshold for electrocutaneous innocuous stimuli was then established using a staircase procedure. Low intensities were initially presented (starting from $0.1 \mathrm{mN}$ ) and increased by $0.1 \mathrm{mN}$ until the first stimulus was detected; then, the intensity was lowered until no longer perceived, and then increased again. The threshold was established after 3 reversals. The intensity used during the experiments was twice the detection threshold. At such intensity, the stimuli do not elicit any painful sensation, and brain responses to them are considered recruiting mainly $A \beta$ fibers. ${ }^{24,26}$ We chose for lowintensity electrical stimuli to compare the effects of low-frequency stimulation (see later) to those of high-frequency stimulation (HFS) on brain responses to $A \beta$ inputs. Indeed, previous reports ${ }^{34}$ have observed that after HFS, brain responses to a variety of somatosensory inputs, even nonnociceptive ones, are enhanced. Furthermore, we always ensured that the elicited sensation was nonpainful, by asking for a rating on a scale ranging from 0 (no sensation) to 100 (the most intense pain imaginable). The rating of 50 constituted an anchor separating nonpainful (0-50) to painful (50-100) sensations. ${ }^{15,33,36-38}$

After establishing the threshold, the EEG net (Philips Electrical Geodesics, Inc) was mounted. Each participant performed 3 sessions, one before the sensitization procedure (ie, LFS) (TO) and 2 after, at 20 (T1) and 45 (T2) minutes after the end of LFS. These time points were in line with previous findings obtained with HFS, ${ }^{36-38}$ and were confirmed by an initial pilot study, in which we tested for mechanical sensitivity from the end of LFS, each 5 minutes until 60 minutes. Low-frequency stimulation was applied to one arm only, the dominant or nondominant one; the arm was counterbalanced across participants. The other arm served as control. At each of the time points (TO, T1, and T2), participants received 3 mechanical pinprick stimuli on both the LFS and control arm, and they were requested to provide an average rating of its intensity on the previously described scale. Participants also received 30 low-intensity electrical stimuli on each arm to elicit SEPs. At the end of the 30 stimuli, a rating of intensity for these stimuli was also asked. The first kind of stimulus that was applied, either mechanical or electrical, and the first stimulated arm, either LFS or control, were counterbalanced across participants.

\subsubsection{Experiment 1}

In experiment 1, participants did not receive any specific instruction for what to do during LFS. Unbeknownst to them at the beginning of the stimulation, we asked for a rating of intensity of the LFS stimuli at the end of the 2-minute stimulation. We also enquired volunteers on whether they used specific strategies during LFS to cope with the painfulness of the stimulation.

\subsubsection{Experiment 2}

Participants in experiment 2 performed an engaging task during LFS, the Eriksen Flanker Task. During this task, participants were shown, on a Philips 32-inch monitor positioned at approximately
$1 \mathrm{~m}, 5$ arrowheads horizontally aligned and were instructed to indicate the direction towards which the central arrow pointed by either pressing the left or right mouse button. The mouse was held on the nonstimulated side. The 4 possible arrowhead combinations $(<<<<,<<><<,>>>>>$, or $>><>>$ ) were presented pseudorandomly. In each trial, the arrowheads were presented for $200 \mathrm{~ms}$ and replaced by a blank screen until either a response was given or the maximal allowed time (1000 ms) was elapsed. The intertrial interval varied randomly between 600 and 1000 ms (mean: 800 ms) (see Ref. 22). At the beginning of the experiment, participants performed 20 familiarization trials (5 for each of the 4 arrow combinations) during which they received a feedback about their performance. The feedback was not available during the actual experiment. The task started 90 seconds before LFS and continued for approximately 90 seconds after LFS. The instruction stressed the importance of both the speed and the accuracy of the response, and these 2 parameters were recorded and analyzed separately for the 3 time periods: pre, during, and post LFS. After the end of the task, we asked participants to judge how engaging and how difficult the task was on a scale from 0 (not difficult/engaging at all) to 10 (as difficult/ engaging as possible). A rating of intensity of the LFS was also obtained. Given that a slightly different number of trials was presented to each participant (depending on the speed of the response), the accuracy was calculated in terms of percentage of correct responses.

\subsubsection{Experiment 3}

Participants in experiment 3 performed a modified version of an $\mathrm{N}$-back task as used by. ${ }^{21}$ They were shown, on the same screen used in experiment 2, a series of letters ( $A$ to $E$ ), each visible for $750 \mathrm{~ms}$, and followed by a 750-ms blank screen. The task was to detect matches between the actual letter and one presented 2 letters before (2-back task). Each string was composed of 15 letters, and the number of matches was pseudorandomized. Participants were additionally requested to retain in memory the number of matches per string, and to report it at the end of the 22.5-second duration of the string. Before the experiment, participants performed a familiarization phase in which 5 strings were presented. During this phase, they received feedback about their performance; the feedback was not provided during the actual experimental phase. Four strings were presented, during the experiment in the "Pre" LFS period, 5 during LFS, and 4 in the "Post" LFS.

Figure 1 summarizes the setup.

\subsection{Statistical analyses}

Statistical analyses were conducted using IBM Statistics SPSS 19 (Armonk, NY: IBM Corp). Assumption of normality was tested using the Wilk-Shapiro test, and the Greenhouse-Geisser correction was used where appropriate.

Changes in the perceived intensity of mechanical pinprick and electrocutaneous stimuli, and in the magnitude of the SEPs (vertex N1 and P2) were assessed using 3 separate analyses of variance with the factors "Time" (3 levels, T0, T1, T2) and "Side" (LFS and control arm). The interaction "Time" $\times$ "Side" was used to investigate the effects of LFS. In case of significant interactions, follow-up t-tests were conducted, and the level of significance of the alpha adjusted by the number of comparisons.

The effect of the "Phase" (pre, during, and post LFS) was assessed on the accuracy of the response and reaction times in the Flanker task. The same effect of the "Phase" was used as 

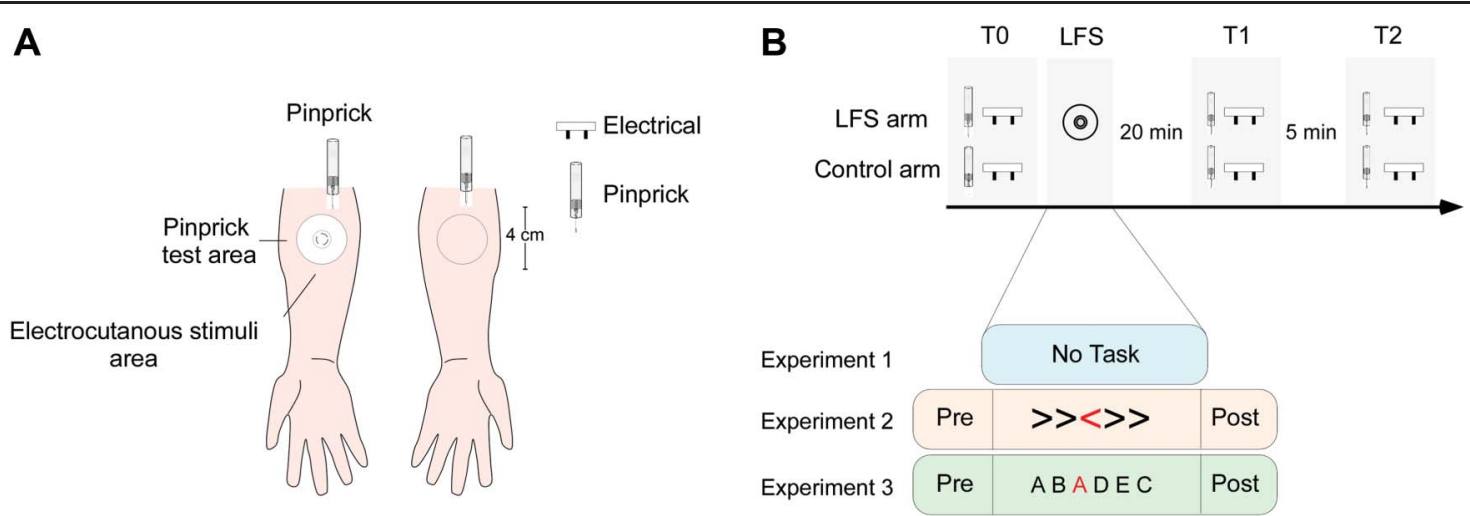

Figure 1. Experimental setup. (A) Participants received, on their volar forearm, 2 kinds of stimuli, before and after an experimental procedure inducing sensitization (ie, LFS of the skin). (B) Three blocks were run for each participant, one before LFS, and 2 after, at 20 minutes (T1) and at 45 minutes (T2) from the end of LFS stimulation. During LFS, participants performed different tasks, depending on the experiment. In experiment 1, no task was performed, in experiment 2 volunteers performed an Eriksen Flanker Task, and in experiment 3 they completed a modified N-Back task. These tasks started before the beginning of LFS and continued after its end. LFS, low-frequency stimulation.

factor for the N-back task; outcome variables were the accuracy of the response, and the deliberation time for the number of matches. Correlations were run using two-tailed Person's $r$ on the pooled data of the 3 experiments.

\section{Results}

\subsection{Questionnaires}

Descriptive statistics for the questionnaires are summarized in Table 1.

\subsection{Thresholds, intensity of stimulation and perceived intensity of low-frequency stimulation}

The intensity of the LFS stimulation was 6.06 ( \pm 2.2$), 7.41$ ( \pm 2.06$)$, and $8.11( \pm 3.21) \mathrm{mN}$, for experiments 1, 2, and 3, respectively. The intensity of the innocuous electrocutaneous stimuli was 1.70 ( \pm 1.52$), 1.37( \pm 0.51)$, and $1.46( \pm 0.53) \mathrm{mN}$, for experiments 1,2 , and 3 , respectively. Low-frequency stimulation was perceived on average as painful in all experiments (experiment 1: $65.30 \pm 13.43$, experiment 2: $68.11 \pm 19.14$, and experiment $3: 66.48 \pm 16.08)$.

\subsection{Cognitive tasks}

We debriefed participants at the end of experiment 1 to understand whether they have used cognitive strategies to cope with the painful sensitizing procedure. Nine participants reported having done so, more specifically: 2 participants tried to slow breathing, 3 counted (either to 8 or made a countdown for the time), 3 tried to rationalize and limit negative thoughts, and one sang a song in his/her head.
Due to a technical problem, data from one participant from experiment 2 were not recorded. Therefore, the data refer to 18 participants for experiment 2 and 21 for experiment 3 . On the 0 to 10 scale investigating how engaging the task was, the Eriksen Flanker task was rated on average $7.61 \pm 1.68$, and the $\mathrm{N}$-back $6.76 \pm 1.51$. This difference was not significant (Mann-Whitney test for independent samples $Z=-1.83 P=0.067$ ). The $\mathrm{N}$-back task was considered more difficult on the same 0 to 10 scale, being rated on average $6.76 \pm 1.37$ vs a $4.28 \pm 2.24$ for the Eriksen Flanker Task (Mann-Whitney test for independent samples $Z=3.33 P<0.001$ ) (see also Supplementary figure 1 , available at http://links.Iww.com/PAIN/A968).

The Flanker task accuracy was $91.07 \pm 12.24 \%, 92.74 \pm$ $11.11 \%$, and $93.97 \pm 12.37 \%$ in the pre, during, and post LFS phases, respectively, and the differences in accuracy in these 3 phases did not reach statistical significance $F(1,17)=1.667, P=$ 0.204 ; partial $\eta^{2}=0.089$. The reaction times for correct answers were of $529.91 \pm 42.99$ ms before, $494.36 \pm 38.83 \mathrm{~ms}$ during, and $511.62 \pm 43.06$ after LFS. These values were significantly different $F(1,17)=10.445, P<0.001$. partial $\eta^{2}=0.381$. Participants became faster, without losing their accuracy during LFS as compared to before $t(17)=4.108, P=0.001$, Cohen's $d=0.86$. Importantly, the reaction times increased significantly again post as compared to during LFS, $\mathrm{t}(17)=$ $-2.490, P=0.023$, Cohen's $d=0.42$, indicating that the effects were not simply due to training.

Reaction times for errors were 439.72 \pm 62.19, $415 \pm 55.36$, and $366.63 \pm 179.29 \mathrm{~ms}$ in the pre, during, and post LFS periods, respectively. This difference was not significant $F_{g-g}(1,13)=0.294 P=0.656$ partial $\eta^{2}=0.022$.

The $\mathrm{N}$-back accuracy reached an average of $45.60 \pm 35.89 \%$, $32.14 \pm 27.63 \%$, and $44.04 \pm 28.12 \%$ correct responses in the pre, during, and post LFS phases, respectively, with no

Table 1

Mean and SDs of the scores at psychological questionnaires.

\begin{tabular}{|c|c|c|c|c|c|}
\hline & IUS total score & PANAS (positive) & PANAS (negative) & LOT-R dispositional & PCS total \\
\hline Experiment 1 & $55.11 \pm 21.46$ & $31.83 \pm 4.99$ & $21.11 \pm 4.89$ & $16.83 \pm 4.21$ & $17.11 \pm 8.20$ \\
\hline Experiment 2 & $57.82 \pm 17.98$ & $30.24 \pm 7.21$ & $19.94 \pm 7.40$ & $13.71 \pm 3.56$ & $14.71 \pm 9.78$ \\
\hline Experiment 3 & $55.14 \pm 17.24$ & $31.62 \pm 7.39$ & $19.81 \pm 6.12$ & $15 \pm 4.29$ & $14.48 \pm 7.78$ \\
\hline
\end{tabular}

A description of the questionnaires is available in the supplementary material (available at http://links.Iww.com/PAIN/A968).

IUS, Intolerance of Uncertainties ${ }^{3}$; LOT-R, Life Orientation Test-Revised ${ }^{18}$; PANAS, Positive and Negative Affect Schedule ${ }^{41}$; PCS, Pain Catastrophizing Scale. ${ }^{23}$ 
statistically significant differences amongst them; $F(1,20)=$ 1.593, $P=0.216$; partial $\eta^{2}=0.074$. Indeed, 6 of 21 participants significantly improved their performance during LFS. Deliberation times for correct answers were $2771 \pm 753,2232 \pm 804$, and $2197 \pm 781 \mathrm{~ms}$, and $2775 \pm 1358,2364 \pm 820$, and $2372 \pm 895$ $\mathrm{ms}$ for incorrect trials. There were no statistically significant differences for incorrect trials $\mathrm{F}(2,30)=0.691, P=0.509$ partial $\eta^{2}=0.044$. Conversely, deliberation times for correct trials significantly differed $\left(F(2,30)=3.690, P=0.042\right.$, partial $\eta^{2}=$ $0.270)$. More specifically, deliberation times decreased from pre to post $\mathrm{t}(13)=3.109 P=0.008$, Cohen's $d=0.54$.

Figure 2 summarizes all these findings.

\subsection{Mechanical hypersensitivity}

\subsubsection{Experiment 1}

A "Time" $\times$ "Side" interaction $(F(2,38)=11.722, P<0.001$ partial $\left.\eta^{2}=0.382\right)$ was observed on the perceived intensity of mechanical pinprick stimuli. Follow-up $t$-tests showed that stimuli applied on the LFS arm were rated as more intense at $\mathrm{T} 1 \mathrm{t}(\mathrm{t}(1))=2.950 P=$ 0.008 , Cohen's $d=0.52$ ) as compared to T0. The increase at T2 did not survive the correction for multiple comparisons (Bonferronicorrected alpha 0.012) $(\mathrm{t}(19)=2.068 P=0.053$, Cohen's $\mathrm{d}=$ 0.33). By contrast, the ratings for the stimuli applied on the control arm remained unchanged from T0 to T1 $(\mathrm{t}(19)=-0.629 P=$ 0.537, Cohen's $d=0.08$ ). A mild habituation, not surviving Bonferroni correction, was observed at T2 $(\mathrm{t}(19)=-2.313 P=$ 0.032 , Cohen's $d=0.28$ ). Including sex as between factor in exploratory analyses did not significantly change the "Time" $\times$ "Side" interaction ( $F=11.416, P<0.001$ partial $\left.\eta^{2}=0.438\right)$.

\subsubsection{Experiment 2}

The results of experiment 2 were similar to those obtained in experiment 1. We observed a "Time" $\times$ "Side" interaction $F(2,36)=$
11.168, $P<0.001$ partial $\left.\eta^{2}=0.383\right)$, explained by an increase in ratings for the stimuli applied at the LFS arm at T1 as compared to T0 $(\mathrm{t}(18)=3.129 P=0.006$, Cohen's $d=0.32)$, but no difference for stimuli applied on the control arm $(\mathrm{t}(18)=1.010 P=0.326$, Cohen's $d=0.07$ ). No difference between T2 and T0 was found (LFS arm t(18) $=1.997 P=0.061$, Cohen's $d=0.22$; control arm $\mathrm{t}(18)=-1.355 P=0.192$, Cohen's $d=0.14)$. Overall, these findings suggest that the cognitive manipulation was ineffective in preventing the development of hypersensitivity at $\mathrm{T} 1$. Similar to experiment 1 , exploratory analysis including sex as a between factor did not significantly change the "Time" $\times$ "Side" interaction ( $F=9.673 P<$ 0.001 partial $\eta^{2}=0.363$ ).

\subsubsection{Experiment 3}

By contrast, in experiment 3, no "Time" $\times$ "Side" interaction was observed $\left(F(2,38)=2.358, P=0.108\right.$ partial $\left.\eta^{2}=0.110\right)$, suggesting that when a high cognitive load working memory task is performed during sensitization, no statistically significant hypersensitivity to mechanical stimuli is developed on the LFS arm at the group level. Also, in this case, exploratory analysis including sex as between factor did not change the results $(F=$ 2.082 $P=0.264$ partial $\eta^{2}=0.104$ ).

Figures 3 and 4 summarize the results. The complete statistics are reported in the supplementary materials (available at http:// links.Iww.com/PAIN/A968).

\subsection{Mechanical hypersensitivity: additional analyses}

The frequentist statistical approach did not allow drawing conclusions about the null hypothesis $(\mathrm{HO})$. To support our conclusion that the probability that there was no interaction effect was larger than the probability there was an interaction effect, we used the Bayesian analysis approach. Bayesian statistics have the advantage of comparing the evidence for the null $(\mathrm{HO})$ and
A

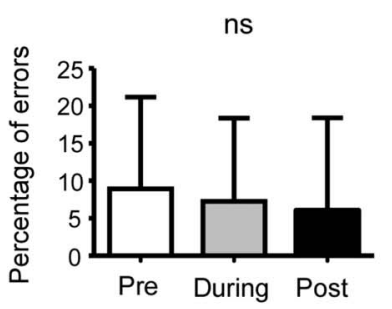

B

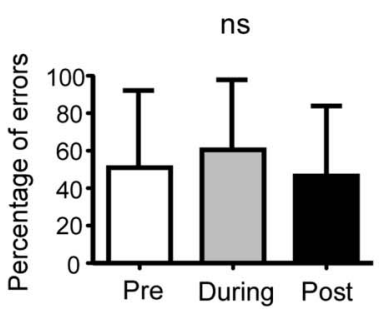

Experiment 2

Flanker Task
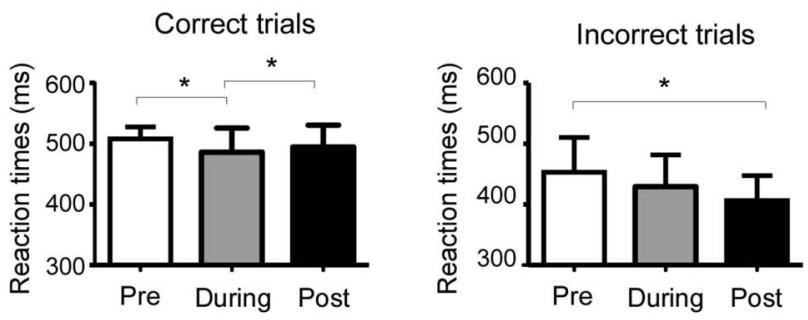

Experiment 3

$\mathrm{N}$-back task

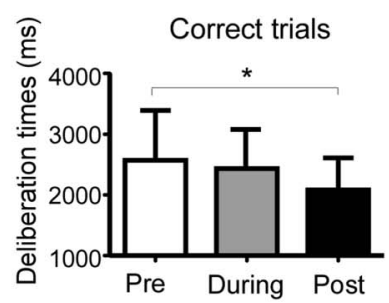

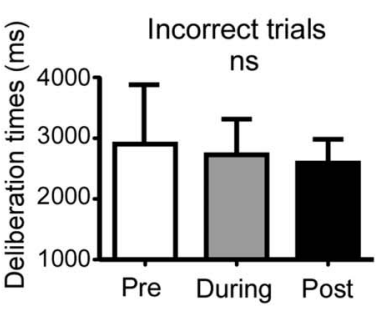

Figure 2. Performance at the tasks. (A) Participants were significantly faster during LFS as compared to before and after for correct trials. Reaction times to incorrect trials diminished across phases. (B) The performance at the N-back task was unchanged during LFS, whereas deliberation time decreased over time. LFS, low-frequency stimulation. 


\section{Experiment 1}

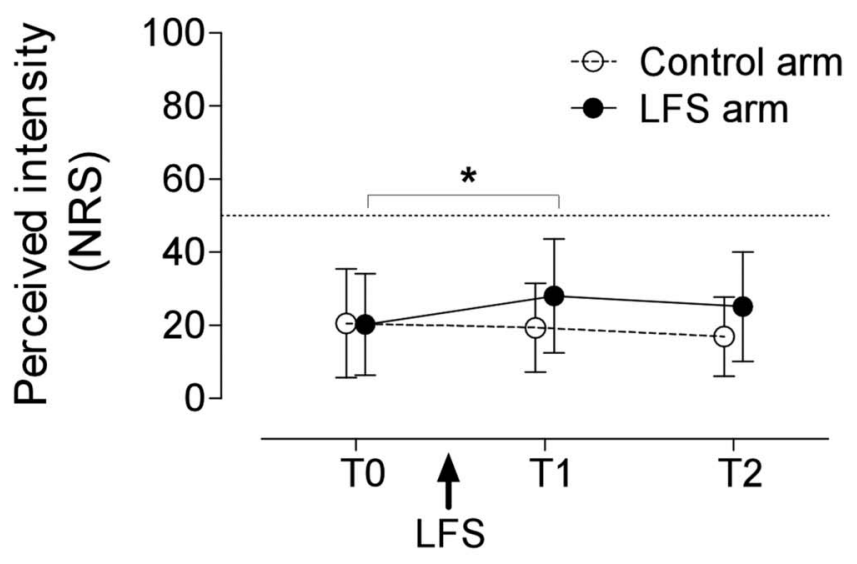

\section{Experiment 2}

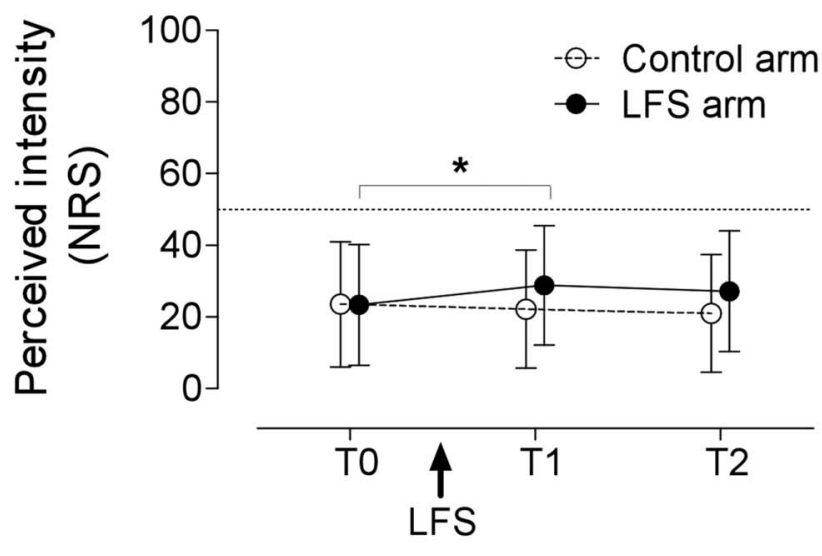

Experiment 3

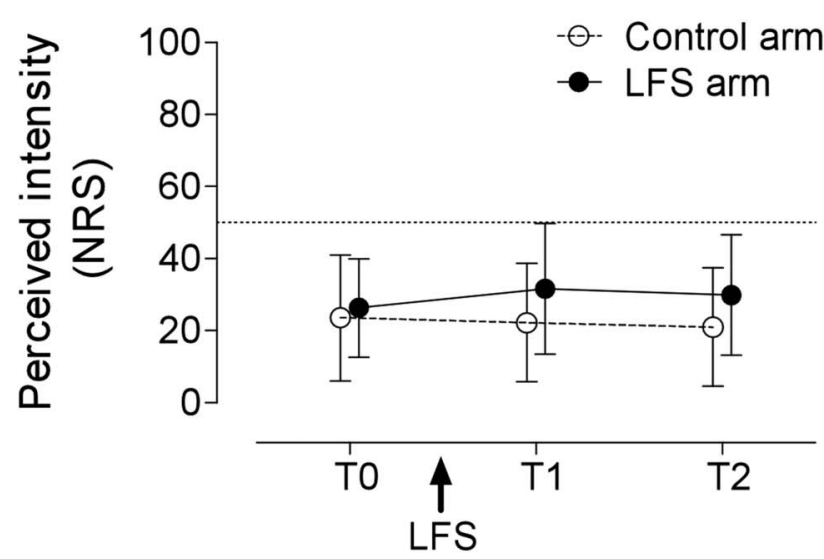

Figure 3. We found a significant Time $\times$ Side interaction in the first 2 experiments driven by a significant increase in the ratings to stimuli applied on the LFS but not on the control arm. By contrast, such interaction was not present for experiment 3. Error bars represent SDs. The dotted line at 50 represents the transition from a nonpainful to a painful domain of sensation. LFS, low-frequency stimulation; NRS, Numerical Rating Scale.

alternative $(\mathrm{H} 1)$ models. ${ }^{39,40}$ Therefore, to further elucidate our results, we performed additional Bayesian analyses focusing on the interaction effects. The analyses were performed by using
JASP (version 0.11) and a default Cauchy prior of 0.707. Bayesian statistics return a Bayes factor for the $\mathrm{HO}$ (B01) and one for the $\mathrm{H} 1$ (B10). To understand the contribution of the interaction, one compares the values of the full model (including the main effects and the interaction) to that including only the main effects. The value that is returned can be conventionally interpreted as follows: values between 1 and 3 indicate "anecdotal" evidence, from 3 to 10 "moderate," from 10 to 30 "strong," and above 30 "very strong." The evidence for the interaction was 5.36 in experiment 1, 6.37 in experiment 2, and 0.45 in experiment 3. In other terms, in experiment 3 , unlike in experiments 1 and 2 , there was substantial evidence against the interaction. The full Bayesian statistics are reported in the supplementary material (available at http://links.Iww.com/PAIN/A968).

\subsection{Tactile sensitivity}

In none of the experiments, a "Time" $\times$ "Side" interaction was observed (experiment $1 \mathrm{~F}(2,38)=-1.925, P=0.160$ partial $\eta^{2}=0.092$; experiment $2 \mathrm{~F}(2,34)=-0.080, P=0.923$ partial $\eta^{2}=0.005$; experiment $3 F(2,40)=-0.611, P=0.548$ partial $\eta^{2}$ $=0.030)$, indicating that LFS had no effect on the reported intensity of innocuous stimuli (Fig. 5).

\subsection{Somatosensory evoked potentials}

\subsubsection{N1 latency and amplitude}

In none of the 3 experiments, a statistically significant "Time" $\times$ "Side" interaction was observed on the latency and amplitude of the N1 component.

\subsubsection{P2 latency and amplitude}

Likewise, no statistically significant "Time" $\times$ "Side" interaction was observed across experiments. The full statistics are provided in the supplementary material (available at http://links.lww.com/ PAIN/A968), and Figure 6 illustrates the results.

\subsection{Correlations}

After pooling all data from the 3 experiments together to increase the numerosity of the cases, we observed a statistically significant correlation between the intensity of the LFS stimulation and the amplitude of the $\mathrm{N} 1$ at the LFS arm at T1 $(r=-0.303, P=0.030$, $\left.R^{2}=0.092\right)$. The correlation at T2 was of $r=-0.274, P=0.051$, $R^{2}=0.075$. No such correlation was found for the P2 (T1; $r=$ $0.129, P=0.364, R^{2}=0.016$; T2: $r=0.149, P=0.295, R^{2}=$ $0.022)$. The amplitude of the N1 at the LFS arm at T1 and the pinprick perception were also uncorrelated $(r=-0.161, P=$ $0.258, R^{2}=0.026$ ). Finally, whereas we found no relationship between the intensity of LFS stimulation and the amount of developed hypersensitivity $\left(r=0.180, P=0.204, R^{2}=0.032\right)$, we did observe a correlation between the perceived intensity of LFS and the amount of hypersensitivity, both at T1 $(r=0.394, P=$ $\left.0.002 R^{2}=0.155\right)$ and T2 $\left(r=0.415, P=0.001 R^{2}=0.172\right)$. Nevertheless, heteroscedasticity was identified in the some of the data (Fig. 8). This calls for a cautious interpretation of the significant linear relationship. Indeed, a reliable linear relationship seems to exist between the perceived intensity of LFS and the development of lower hypersensitivity scores. However, for higher perceived LFS intensity scores, such linear relationship is disrupted.

Figures 7 and 8 summarize the results. 


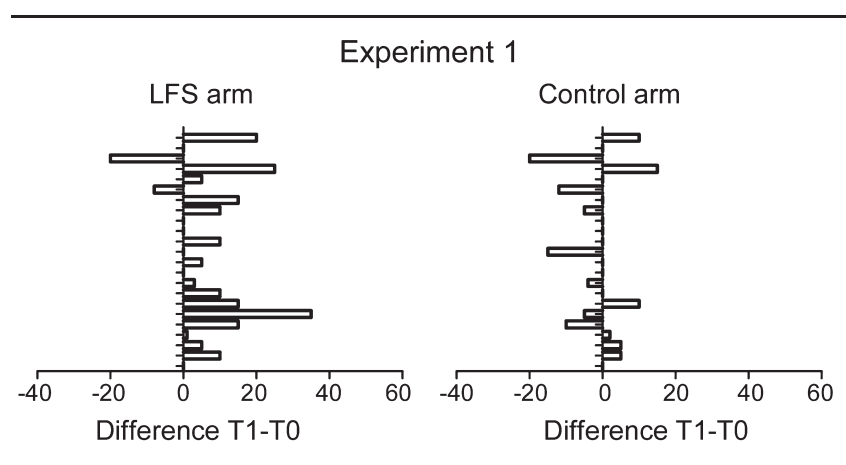

Experiment 2
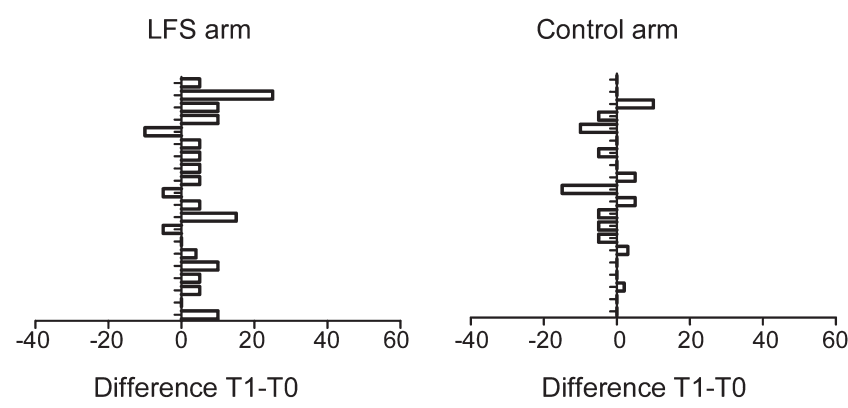

Experiment 3
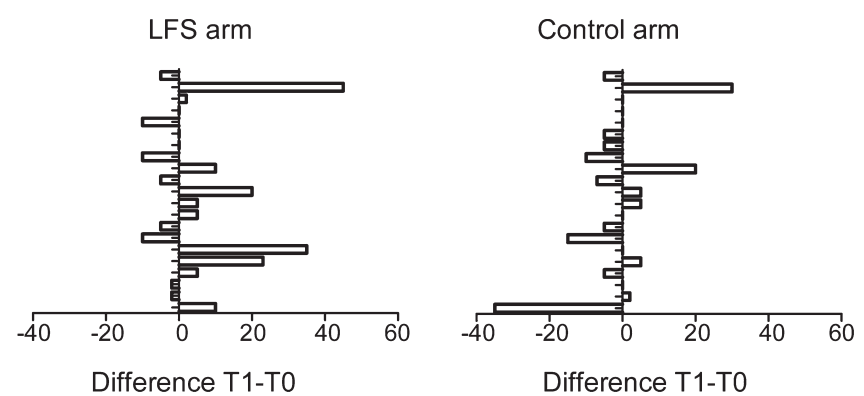

Figure 4. Details of the results at the individual level. Bars represent the scores provided for the pinprick stimulation. Negative values indicate lower scores at T1 as compared to T0.

\section{Discussion}

Despite their clinical value, reports investigating whether, how, and which cognitive factors contribute to the development of hypersensitivity/hyperalgesia are still scarce. ${ }^{14,17,31}$ Furthermore, the neural mechanisms of such effects, if they exist, largely remain to be elucidated. ${ }^{10}$ In this study, we have tested, for the first time, in 3 separate studies, whether being engaged in non-pain-related cognitive tasks during sensitization results in the abolishment of the significant interaction Time $\times$ Side typically occurring after sensitization at T1 and T2. To achieve our aim, we have first validated, in humans, a novel protocol to induce hypersensitivity using LFS at $2 \mathrm{~Hz}$ for 2 minutes (experiment 1). Subsequently, in experiments 2 and 3 , we have requested participants to engage in cognitive tasks of increasing difficulty while they underwent LFS. We have measured both the increase in perceived intensity of pinprick stimuli and brain responses to innocuous electrocutaneous stimuli (SEPs). Indeed, previous studies using HFS of the skin, another procedure that has shown to induce robust hyperalgesia, have reported that, after sensitization, the middle latency (120-200 ms) negative component of the event-related potentials measured at the vertex $(\mathrm{Cz})$ was increased for

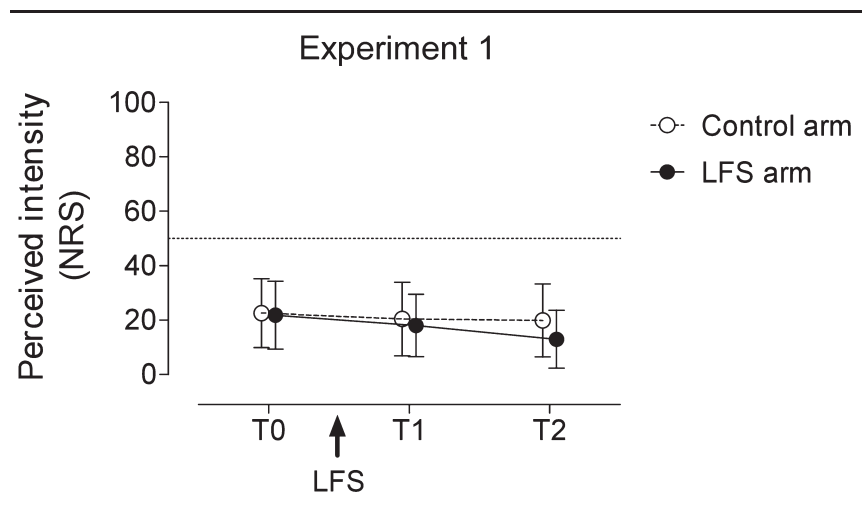

Experiment 2

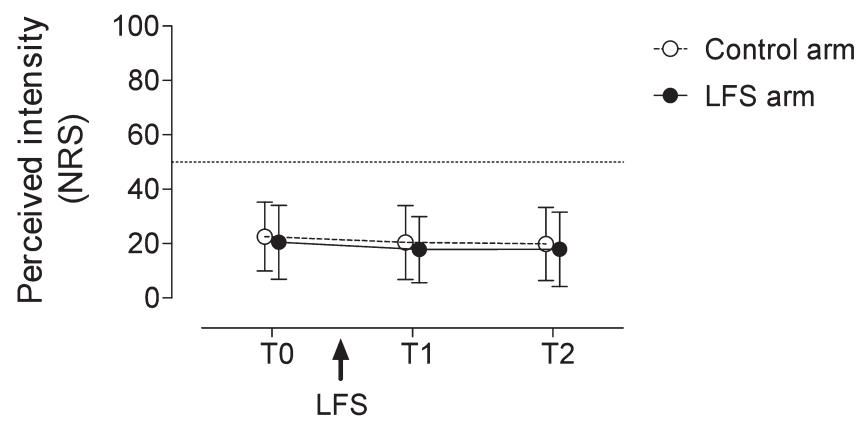

Experiment 3

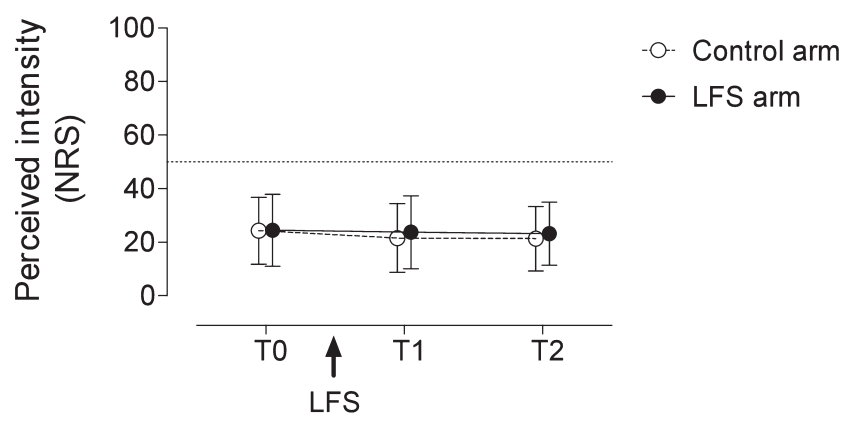

Figure 5. Low-frequency stimulation did not influence the ratings to innocuous electrical stimuli, as evidenced by the lack of interaction between Time and Side in all 3 experiments. Error bars represent SDs. The dotted line at 50 represents the transition from a non-painful to a painful domain of sensation. LFS, low-frequency stimulation; NRS, Numerical Rating Scale.

a broad range of somatosensory and nonsomatosensory, ie, visual stimuli. 27,30,33,34,36

Our results show that mechanical hypersensitivity can still develop when a moderately engaging response-inhibition task is performed during LFS. However, no significant Time $\times$ Side interaction was observed when a more difficult working memory task (an N-back task) was administered during sensitization. This evidence shows that the concomitant execution of certain cognitive tasks interferes with a significant development of mechanical hypersensitivity.

The present findings also do not support the possibility that LFS, in contrast with what is observed with HFS, induces an increase in the magnitude of the middle latency component of the event-related potentials. This, together with the lack of correlation between the N1 elicited by stimuli applied on the LFS arm at T1 and the perceived pinprick intensity for stimuli applied on the same arm also at T1, suggests that the increase in the middle latency component and the increase in perceived intensity of mechanical stimuli reflect 2 distinct processes. 


\section{Experiment 1}
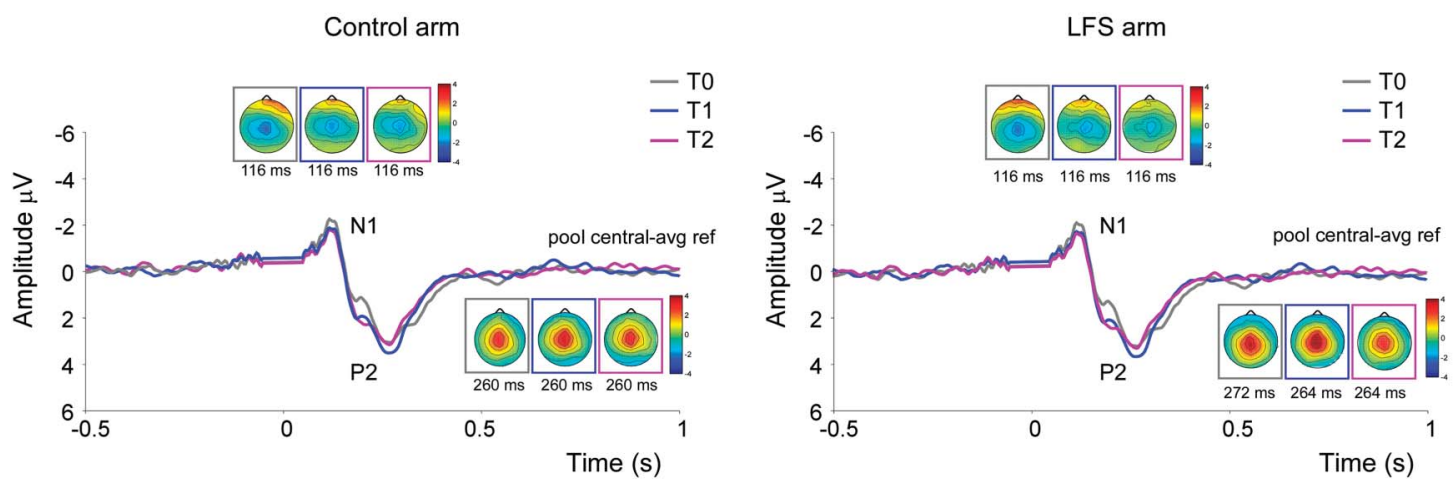

\section{Experiment 2}
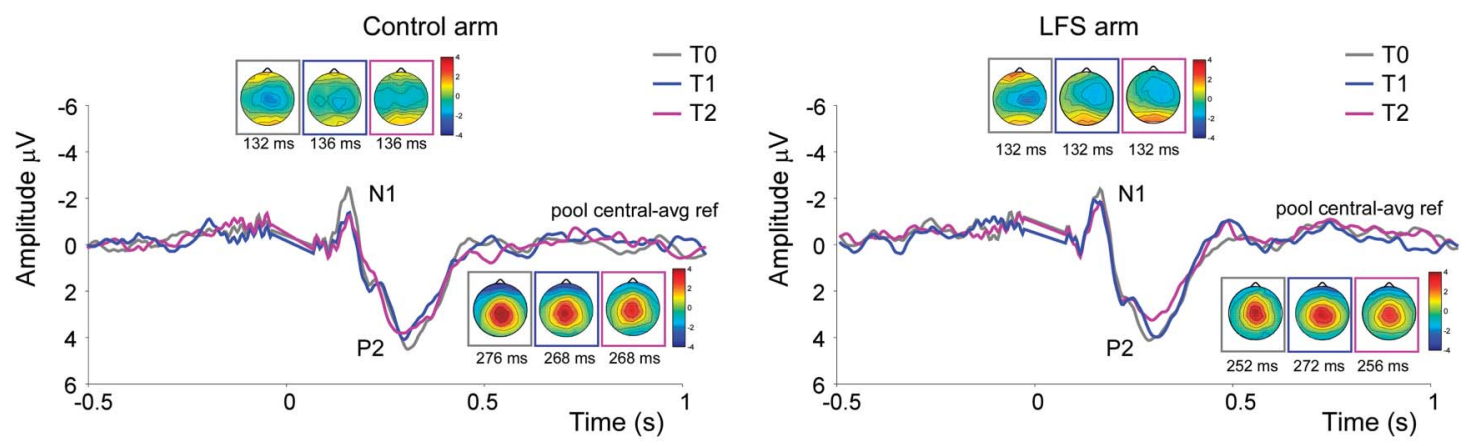

\section{Experiment 3}
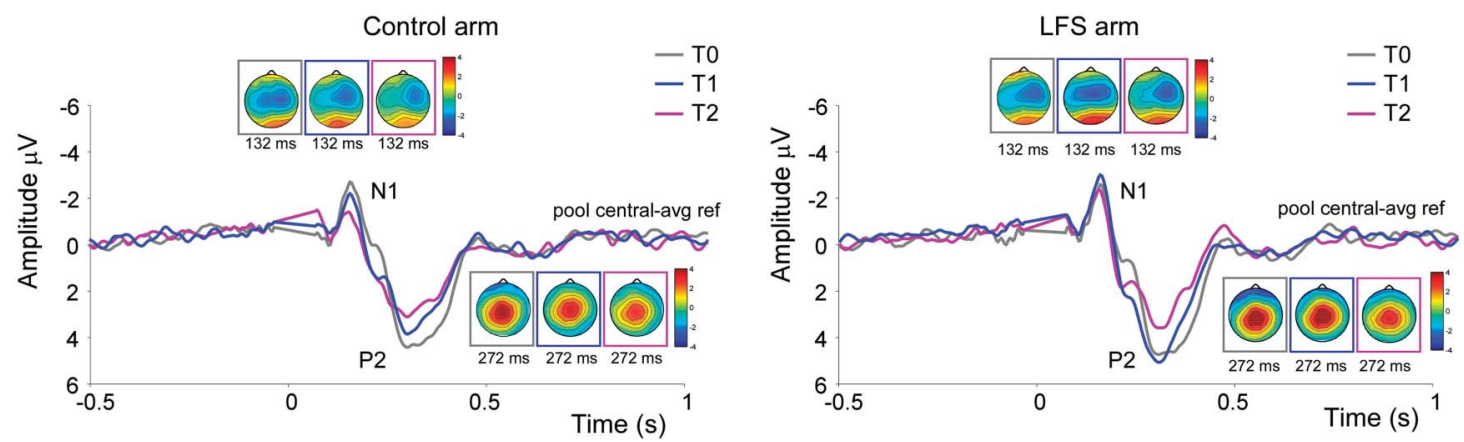

Figure 6. In contrast with previous studies using a different frequency to induce CS, we did not observe an increase of the N1 and P2 components of the SEPs. The electrical artifact around 0 seconds has been suppressed in the figure for visualization purposes. CS, central sensitization; SEP, somatosensory-evoked potential.

\subsection{Low-frequency stimulation induces mechanical hypersensitivity}

Electrical stimulation of the skin, as compared to capsaicin, has the advantage of inducing hypersensitivity without triggering an ongoing burning sensation that can per se capture attention. For its characteristics of brevity and intensity, HFS did not represent the best model to test top-down inhibitory effects as the whole procedure lasts 50 seconds, of which only 5 of intense painful stimuli. Therefore we validated, in humans, the protocol proposed by lkeda et al. ${ }^{7}$ The authors demonstrated, in vitro, that both HFS and LFS of the skin induce increased postsynaptic potential in nociceptive pathways, with LFS sensitizing the spinoperiaqueductal gray pathway instead of the spinoparabrachial pathway. We observed in humans that such a protocol, at $2 \mathrm{~Hz}$ for 2 minutes, is also capable of inducing a significant hypersensitivity to pinprick mechanical stimuli. This is also in line with other reports showing that, in humans, both LFS and HFS of the skin may result in a facilitation of nociceptive processing. ${ }^{2,4}$ For instance, Biurrun-Manresa et $\mathrm{al}^{2}{ }^{2}$ showed that LFS induced a long-lasting facilitation of the nociceptive withdrawal reflex, which is considered a measure of spinal nociceptive processing (however, for contradicting findings, see Ref. 9).

\subsection{Low-frequency stimulation does not induce an increase of the vertex negative middle latency component}

Somatosensory-evoked potentials were not enhanced after LFS. Accumulating evidence shows that the increase in SEPs coexists with, but is probably not a correlate of, hypersensitivity and hyperalgesia. ${ }^{1}$ Indeed, albeit to a lesser extent, an enhancement 
$\mathrm{T} 1$
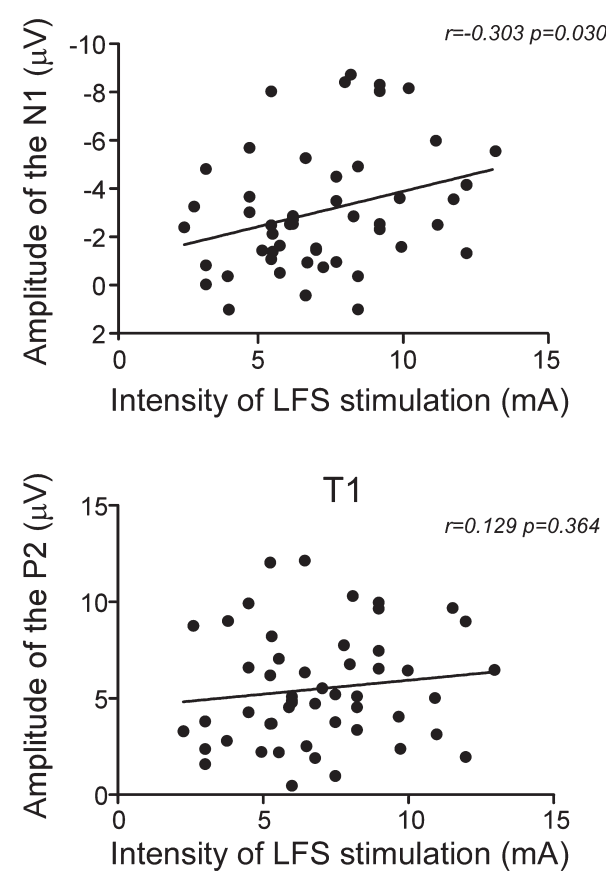

T2
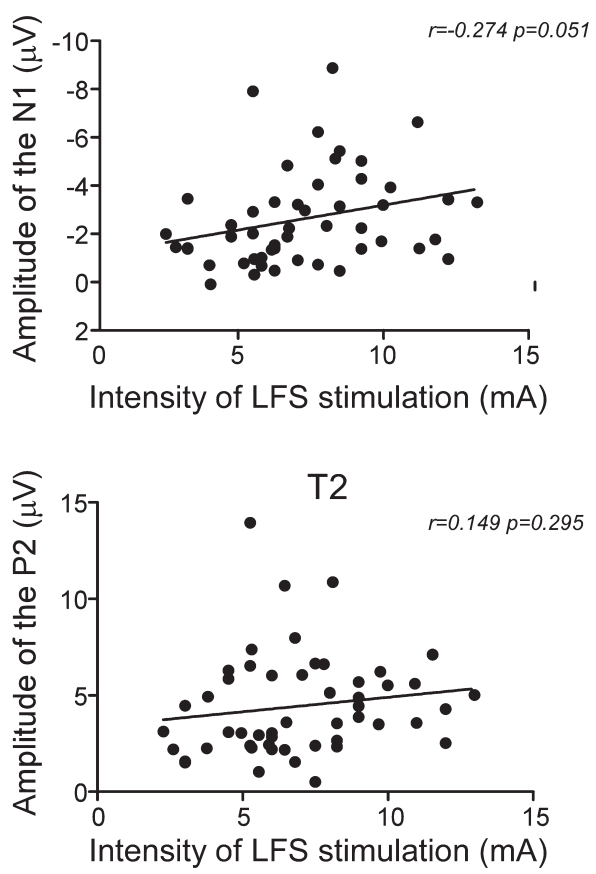

Figure 7. We observed significant correlations between the LFS intensity of stimulation and the amplitude of the signal (N1) at T1 and, marginally, at T2. No such correlation was observed for the amplitude of the P2. The correlations are calculated on the data of the 3 pooled experiments. LFS, low-frequency stimulation.

in the magnitude of cortical potentials in response to stimuli presented on the sensitized arm has been also observed for visual stimuli, ${ }^{27}$ and changes in brain responses are uncorrelated with the changes in pain reports. ${ }^{1}$ Currently, it remains unclear which processes lead to an increase in the magnitude of the brain response after HFS and capsaicin. ${ }^{25,32,33,35}$ A previous study ${ }^{25}$ investigated whether sensitization procedures (HFS in that case) would increase attentional allocation towards the sensitized arm, thereby resulting in a prioritization of stimuli presented on the sensitized arm over those presented on the control arm. Surprisingly, the findings did not uphold the hypothesis, questioning whether the increase in the middle latency component represents an indirect reflection of perceptual biases towards the sensitized arm.

\subsection{Secondary mechanical hypersensitivity is reduced when a high load working memory task is performed concomitantly with the sensitization procedure}

The main finding of the present study is that the amount of mechanical hypersensitivity that develops after LFS is modulated by the concomitant execution of a difficult cognitive task. In more detail, our data indicate that cognitive shielding against intense/ prolonged stimuli inducing hypersensitivity is effective in some individuals. Previous studies have suggested that some individuals are better at remaining engaged in a task (attention types, Atypes) while painful stimuli are presented, whereas others are more easily distracted by the pain (pain type, P-types). ${ }^{6,20}$ An interesting possibility is that similar features play a role in the development of hypersensitivity as well. Of note, the present

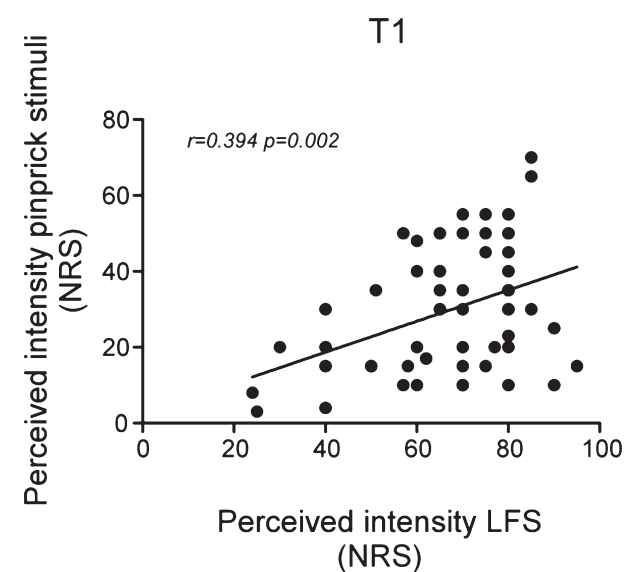

(NRS)
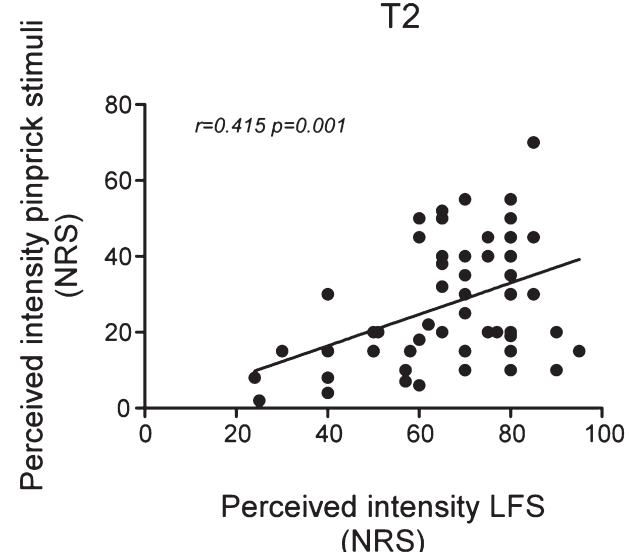

(NRS)

Figure 8. At both T1 and T2, the amount of hypersensitivity was associated with the perceived intensity of LFS during sensitization, rather than with the actual LFS intensity that was used. The correlations are calculated on the data of the 3 pooled experiments. LFS, low-frequency stimulation. 
cognitive task was not individually tailored for difficulty; future studies may investigate whether cognition has a limited modulatory effect, ie, only "A-type" individuals may benefit from cognitive shielding or whether the proper balance between the perceived pain intensity and the difficulty of the task may contribute to exert analgesic effects in every participant. Moreover, considering the fact that we did not use the same task with increasing levels of difficulties, but 2 different tasks that were rated as having 2 different levels of difficulty, we cannot be certain of the underlying mechanisms that led to the lack of significant interaction in the group performing the $\mathrm{N}$-back task. One possibility is that the $\mathrm{N}$-back task had a higher cognitive load, and hence required more attention to be successfully performed. In line with this view, previous evidence showed that the execution of a high load working memory N-back task (the same we used) interferes more strongly with BOLD responses at the spinal level after the administration of a nociceptive heat laser stimulus, ${ }^{21}$ as compared to a low-load version of the same task. An alternative possibility to explain our results is that working memory, but not response inhibition capacities, interferes with the development of mechanical hyperalgesia. Finally, it may be that not only an N-back task, but other difficult tasks as well, become arousing enough to impart "hypoalgesic" effects. Therefore, future studies are required to systematically examine the task specificity of cognitive load induction procedures.

Two caveats should also be put forward. First, due to the necessity to first validate the LFS procedure, the 3 experiments were conducted one after the other in 3 groups (between design), leading to our methodological choice of analyzing them separately. Second, our analysis of interest was the identification of a Time $\times$ Side interaction in the perception of mechanical stimuli, and this interaction did not reach the statistical significance in the third experiment. Nevertheless (see supplementary material, available at http://links.Iww.com/PAIN/A968), a main effect of time was observed, driven by significant differences between the 2 arms at T1 and T2. This result indicates that hyperalgesia still developed in some individuals. Moreover, due to the methodological choice of analyzing the 3 experiments separately, we refrain from making direct comparisons across them. In this sense, we cannot conclude that more hyperalgesia developed in experiment 1 than in experiment 3. Nonetheless, we report all the individual results, and the likelihood of the $\mathrm{HO}$ hypothesis in the 3 experiments using Bayesian statistics. These results support the possibility that the lack of significant interaction in experiment 3 is not merely due to lack of power. Replication studies using a randomized design are needed to further validate the present results.

\subsection{Modulating hypersensitivity: different strategies, different mechanisms?}

Two previous studies using repeated administration of heat painful stimuli to induce hypersensitivity/ hyperalgesia showed that placebo manipulations ${ }^{14}$ as well as short sessions of repeated cognitive behavioral therapy over 8 days ${ }^{17}$ were effective in reducing the amount of hyperalgesia. These results indicate that expectations play a major role in the development of hyperalgesia, as shown by a report by van den Broeke et al. ${ }^{31}$ In this latter study, the authors demonstrated that a mere verbal suggestion was able, in a nocebo group vs a control group, to increase the perceived intensity of mechanical stimuli after HFS. The previous literature also indicated that reappraising the meaning of the pain experience, associating it with positive instead of negative thoughts, reduced unpleasantness ratings to painful stimuli and the extent of secondary hyperalgesia across sessions. ${ }^{17}$ These latter effects were correlated with a reduction in pain catastrophizing. ${ }^{17}$ Whether expectations, reappraisal, cognitive load, difficult of the task, cognitive abilities recruited by task, and/or arousal interfere with the development of hypersensitivity through the same or different mechanisms remains currently an open question. However, one important methodological difference is that both studies ${ }^{14,17}$ included several sessions across days. By contrast, our study is the first one reporting that, at a group level, sensitivity to mechanical stimuli may not increase significantly when a difficult working memory task is performed during sensitization, suggesting that at least part of the development of hypersensitivity/hyperalgesia is modulated by mechanisms involved in the execution of a difficult $\mathrm{N}$-back task.

To conclude, LFS can be used as an alternative method to induce hypersensitivity to mechanical stimuli, and the concomitant execution of a high load and difficult working memory $\mathrm{N}$ back task can modulate such effects in certain individuals.

\section{Conflict of interest statement}

The authors have no conflicts of interest to declare.

\section{Acknowledgments}

The authors thank Jeroen Clarysse for his help with programming the experiments. D.M. Torta, A. von Leupoldt, and J.W.S. Vlaeyen were supported by an "Asthenes" long-term structural funding-Methusalem grant (Meth/15/011) by the Flemish government, Belgium. EVDB was supported by the Fonds de Recherche Clinique (UC Louvain).

\section{Appendix A. Supplemental digital content}

Supplemental digital content associated with this article can be found online at http://links.Iww.com/PAIN/A968.

\section{Article history: \\ Received 10 July 2019}

Received in revised form 2 January 2020

Accepted 10 January 2020

Available online 24 February 2020

\section{References}

[1] Biurrun Manresa J, Kaeseler Andersen O, Mouraux A, van den Broeke EN. High frequency electrical stimulation induces a long-lasting enhancement of event-related potentials but does not change the perception elicited by intra-epidermal electrical stimuli delivered to the area of increased mechanical pinprick sensitivity. PLoS One 2018;13: e0203365.

[2] Biurrun Manresa JA, Morch CD, Andersen OK. Long-term facilitation of nociceptive withdrawal reflexes following low-frequency conditioning electrical stimulation: a new model for central sensitization in humans. Eur J Pain 2010;14:822-31.

[3] Buhr K, Dugas MJ. The Intolerance of Uncertainty Scale: psychometric properties of the English version. Behav Res Ther 2002;40:931-45.

[4] De Col R, Maihofner C. Centrally mediated sensory decline induced by differential C-fiber stimulation. PAIN 2008;138:556-64.

[5] Eccleston C, Crombez G. Pain demands attention: a cognitive-affective model of the interruptive function of pain. Psychol Bull 1999;125:356-66.

[6] Erpelding N, Davis KD. Neural underpinnings of behavioural strategies that prioritize either cognitive task performance or pain. PAIN 2013;154: 2060-71.

[7] Ikeda H, Stark J, Fischer H, Wagner M, Drdla R, Jager T, Sandkuhler J. Synaptic amplifier of inflammatory pain in the spinal dorsal horn. Science 2006;312:1659-62. 
[8] Jung TP, Makeig S, Humphries C, Lee TW, McKeown MJ, Iragui V, Sejnowski TJ. Removing electroencephalographic artifacts by blind source separation. Psychophysiology 2000;37:163-78.

[9] Klein T, Magerl W, Hopf HC, Sandkuhler J, Treede RD. Perceptual correlates of nociceptive long-term potentiation and long-term depression in humans. J Neurosci 2004;24:964-71.

[10] Kucyi A, Salomons TV, Davis KD. Cognitive behavioral training reverses the effect of pain exposure on brain network activity. PAIN 2016;157: 1895-904.

[11] Kuttikat A, Noreika V, Chennu S, Shenker N, Bekinschtein T, Brown CA. Altered neurocognitive processing of tactile stimuli in patients with complex regional pain syndrome. J Pain 2018;19:395-409.

[12] Legrain V, Crombez G, Mouraux A. Controlling attention to nociceptive stimuli with working memory. PLoS One 2011;6:e20926.

[13] Legrain V, Crombez G, Plaghki L, Mouraux A. Shielding cognition from nociception with working memory. Cortex 2013;49:1922-34.

[14] Matre D, Casey KL, Knardahl S. Placebo-induced changes in spinal cord pain processing. J Neurosci 2006;26:559-63.

[15] Mouraux A, Plaghki L. Are laser-evoked brain potentials modulated by attending to first or second pain? PAIN 2007;129:321-31.

[16] Romero YR, Straube T, Nitsch A, Miltner WH, Weiss T. Interaction between stimulus intensity and perceptual load in the attentional control of pain. PAIN 2013;154:135-40.

[17] Salomons TV, Moayedi M, Erpelding N, Davis KD. A brief cognitivebehavioural intervention for pain reduces secondary hyperalgesia. PAIN 2014;155:1446-52.

[18] Scheier MF, Carver CS, Bridges MW. Distinguishing optimism from neuroticism (and trait anxiety, self-mastery, and self-esteem): a reevaluation of the Life Orientation Test. J Personal Soc Psychol 1994;67:1063-78.

[19] Schrooten MG, Van Damme S, Crombez G, Peters ML, Vogt J, Vlaeyen JW. Nonpain goal pursuit inhibits attentional bias to pain. PAIN 2012;153: 1180-6.

[20] Seminowicz DA, Mikulis DJ, Davis KD. Cognitive modulation of painrelated brain responses depends on behavioral strategy. PAIN 2004;112: 48-58.

[21] Sprenger C, Eippert F, Finsterbusch J, Bingel U, Rose M, Buchel C. Attention modulates spinal cord responses to pain. Curr Biol 2012;22: 1019-22.

[22] Sucec J, Herzog M, Van Diest I, Van den Bergh O, von Leupoldt A. The impact of dyspnea and threat of dyspnea on error processing. Psychophysiology 2019;56:e13278.

[23] Sullivan M, Bishop S, Pivik J. The pain catastrophizing scale: development and validation. Psychol Assess 1995;7:524-32.

[24] Torta DM, Churyukanov MV, Plaghki L, Mouraux A. The effect of heterotopic noxious conditioning stimulation on Adelta-, C- and Abetafibre brain responses in humans. Eur J Neurosci 2015;42:2707-15.

[25] Torta DM, Filbrich L, Van Den Broeke EN, Legrain V. No perceptual prioritization of non-nociceptive vibrotactile and visual stimuli presented on a sensitized body part. Sci Rep 2018;8:5359.

[26] Torta DM, Legrain V, Mouraux A. Looking at the hand modulates the brain responses to nociceptive and non-nociceptive somatosensory stimuli but does not necessarily modulate their perception. Psychophysiology 2015; 52:1010-18.
[27] Torta DM, Van Den Broeke EN, Filbrich L, Jacob B, Lambert J, Mouraux A. Intense pain influences the cortical processing of visual stimuli projected onto the sensitized skin. PAIN 2017;158:691-7.

[28] Treede RD. Gain control mechanisms in the nociceptive system. PAIN 2016;157:1199-204.

[29] Van Damme S, Legrain V, Vogt J, Crombez G. Keeping pain in mind: a motivational account of attention to pain. Neurosci Biobehavioral Rev 2009;34:204-13.

[30] van den Broeke EN, de Vries B, Lambert J, Torta DM, Mouraux A. Phaselocked and non-phase-locked EEG responses to pinprick stimulation before and after experimentally-induced secondary hyperalgesia. Clin Neurophysiol 2017;128:1445-56.

[31] van den Broeke EN, Geene N, van Rijn CM, Wilder-Smith OH, Oosterman J. Negative expectations facilitate mechanical hyperalgesia after highfrequency electrical stimulation of human skin. Eur J Pain 2014;18:86-91.

[32] van den Broeke EN, Hartgerink MD, Butler J, Lambert J, Mouraux A. Central sensitization increases the pupil dilation elicited by mechanical pinprick stimulation. J Neurophysiol 2019;122:994-1001.

[33] van den Broeke EN, Lambert J, Huang G, Mouraux A. Central sensitization of mechanical nociceptive pathways is associated with a long-lasting increase of pinprick-evoked brain potentials. Front Hum Neurosci 2016;10:531.

[34] Van Den Broeke EN, Mouraux A. High frequency electrical stimulation of human skin induces heterotopical mechanical and heat hyperalgesia and enhanced responses to vibrotactile input. J Neurophysiol 2014;111: 1564-73.

[35] van den Broeke EN, Mouraux A, Groneberg AH, Pfau DB, Treede RD, Klein T. Characterizing pinprick-evoked brain potentials before and after experimentally induced secondary hyperalgesia. J Neurophysiol 2015; 114:2672-81.

[36] van den Broeke EN, van Heck CH, Ceelen LA, van Rijn CM, van Goor H, Wilder-Smith $\mathrm{OH}$. The effect of high-frequency conditioning stimulation of human skin on reported pain intensity and event-related potentials. J Neurophysiol 2012;108:2276-81.

[37] van den Broeke EN, van Heck CH, van Rijn CM, Wilder-Smith OH. Neural correlates of heterotopic facilitation induced after high frequency electrical stimulation of nociceptive pathways. Mol Pain 2011;7:28.

[38] van den Broeke EN, van Rijn CM, Biurrun Manresa JA, Andersen OK, Arendt-Nielsen L, Wilder-Smith $\mathrm{OH}$. Neurophysiological correlates of nociceptive heterosynaptic long-term potentiation in humans. J Neurophysiol 2010;103:2107-13.

[39] Wagenmakers EJ, Marsmam M, Jamil T, Ly A, Verhagen J, Love J, Selker R, Gronau QF, Šmíra M, Epskamp S, Matzke D, Rouder JN, Morey RD. Bayesian inference for psychology. Part I: theoretical advantages and practical ramifications. Psychon Bull Rev 2018;25:35-57.

[40] Wagenmakers EJ, Love J, Marsman M, Jamil T, Ly A, Verhagen J, Selker R, Gronau QF, Dropmann D, Boutin B, Meerhoff F, Knight P, Raj K, van Kesteren EJ, van Doorn J, Šmíra M, Epskamp S, Etz A, Matzke D, de Jong T, van den Bergh D, Sarafoglou A, Steingroever H, Derks K, Rouder JN, Morey RD. Bayesian inference for psychology. Part II: example applications with JASP. Psychon Bull Rev 2018;25:58-76.

[41] Watson D, Clark LA, Tellegen A. Development and validation of brief measures of positive and negative affect: the PANAS scales. J Personal Soc Psychol 1988;54:1063-70. 